\title{
La Constitución gaditana de 1812 y su proyección en los movimientos liberales europeos del primer tercio del siglo $\mathrm{XIX}^{\star}$
}

\author{
IRENE CASTELLS OLIVÁN \\ Universidad Autónoma. Barcelona
}

\section{LA CONSTITUCIÓN DE 1812 Y SU IMPACTO INMEDIATO}

Con la Constitución de 1812 culmina el proceso revolucionario abierto en España por la invasión napoleónica de 1808, que provocó a un tiempo tres grandes reacciones-efectos: a) la quiebra de la antigua organización social y política, b) una guerra de resistencia nacional contra el francés, conocida por la Guerra de la Independencia; y c) la primera experiencia liberal en nuestro país. Es decir, crisis del Antiguo Régimen, guerra y revolución a la vez. Guerra de resistencia nacional, interclasista por tanto, en la que las fuerzas absolutistas luchaban al lado de los sectores ilustrados y liberales, pero también coyuntura revolucionaria al permitir que una minoría liberal, "los hombres más progresivos de España" según Marx (1), se reunieran en Cádiz, único territorio nacional libre del invasor, para desde allí promulgar una Constitución que transcendería su propio marco y contexto y se convertiría desde entonces en un hito histórico, no sólo para España, sino para toda la Europa de la época.

La victoria española contra Napoleón, propagador de los principios de la révolución de 1789, pero confiscador de las mismas libertades que la revolución consagró, fue un hecho insólito e inesperado que tuvo gran resonancia en Europa e hizo de la guerra de la independencia - guerra

(*) Conferencia pronunciada en la Universidad de Verano de Cádiz, el 18 de julio de 1987, en el marco del tema "El Cádiz de las Cortes".

(1) K. MARX - F. ENGELS, Revolución en España, Moscú, 1978, pág. 462. 
del pueblo con su original y sorprendente fórmula de guerrillas-, un modelo a imitar por los movimientos nacionalistas del siglo XIX (2).

El mito de España, que al sepultar a los ejércitos napoleónicos se cubría de gloria ante la atónita Europa, era sin embargo ambiguo, como ambigua fue la lucha contra Napoleón, al igual que su obra. Lucha que se hizo a un tiempo - y ésta es su gran ambigüedad- en nombre de la libertad y en el de la legitimidad de las monarquías absolutistas del Antiguo Régimen. Eso explica que en julio de 1812, el autócrata zar de Rusia fuera el primero en reconocer la Constitución de 1812 (3). Pero no era menos cierto también que los principios de la revolución francesa se habían impuesto con el código gaditano, texto que no fue en absoluto una simple copia de los textos franceses, sino que, por el contrario, había querido inspirarse en la tradición progresista medieval española, lo que mereció ser calificado por uno de los grandes analistas del período, como de una "reproducción de los fueros antiguos, pero leídos a la luz de la revolución francesa y adaptados a las demandas de la sociedad moderna" (4). Así lo expresaba Marx. Todo ello en un contexto muy específico en que la ausencia del rey permitió a los liberales imponerle un texto limitador de sus prerrogativas. Esta era la novedad que aportaba nuestra constitución gaditana, lo que para la oposición intelectual europea al Antiguo Régimen supondría un verdadero programa ideológico, en torno a tres ideas que aparecían como un todo inseparable en la constitución de 1812: Libertad, Nación y Constitución.

Frente a ello surgió la reacción europea de 1814. La cínica promesa por parte de las fuerzas absolutistas de conceder constituciones, había sido utilizada como arma de propaganda política contra el común tirano

(2) G. SPINI, Mito e realtà della Spagna nelle Rivoluzioni italiane del 1820-21, Roma, 1950, sitúa el mito de la guerra de guerrillas en la literatura que surgió en torno a la lucha del pueblo español contra la dominación extranjera en los años que siguieron a la caída de Napoleón. El italiano Carlo Bianco di Saint-Jorioz, liberal piamontés que luchó en España en 1823 por la defensa del régimen constitucional, aplicando estas experiencias a los problemas de la independencia italiana, escribió la obra que, con el título Della guerra nazionale di insurrezione per bande, se publicó en Marsella en 1830.

(3) J. FERRANDO BADIA, "Vicisitudes e influencias de la Constitución de 1812», Revista de Estudios Políticos, n."126, Madrid, 1962, pp. 187-188.

(4) K. MARX - F. ENGELS, op. cit., p. 42. Con esta opinión de Marx de que la Constitución de 1812 fue una síntesis entre innovación y tradición histórica, está de acuerdo en la actualidad la mayor parte de la historiografía sobre el tema, tras una larga polémica que arranca del mismo período de las Cortes de Cádiz. Véase un estado de la cuestión en M. ${ }^{2}$ E. MARTÍNEZ QUINTEIRO, "En torno al primer Constitucionalismo

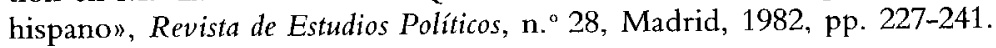


Napoleón. No fue nada extraño, por tanto, el que una vez derrotado el imperio de aquél, y vueltos a sus tronos los antiguos príncipes, éstos se volvieran en contra de la Constitución y no aceptaran ser soberanos constitucionales, sino que retornaron a su concepción patrimonial del estado, queriendo ver los acontecimientos europeos ocurridos desde 1789 sólo como un dramático paréntesis. De ahí la revancha furiosa que ejercieron desde 1814, incluso sobre aquellos que les habían «ayudado» en la lucha contra Napoleón, tal como hizo en España Fernando VII con los liberales gaditanos, anulando toda la obra de la Constitución de 1812, en mayo de 1814, al regresar de su cautiverio francés.

Monarcas, nobleza legítimista y eclesiásticos reaccionarios, unidos todos en la llamada alianza del trono y del altar, desencadenaron una desaforada campaña de desprestigio de la democracia y, bajo pretexto de la ignorancia del pueblo, se dedicaron a ridiculizar desde 1814 la ideología constitucional.

Pretendían en realidad recuperar el poder y el terreno político perdidos, marginando a las élites burguesas en sus aspiraciones por ejercer una función directiva en el estado. En este contexto creado a nivel internacional tras la derrota de Napoleón, se comprende que siendo España un país mayoritariamente feudal a nivel socio-económico, la correlación de fuerzas pendulara rápidamente a favor del asolutismo, que recuperó en su beneficio la crisis abierta en 1808 .

Se inició así, en 1814-1815, un período de involución, sobre todo a nivel político, que desde este momento va a caracterizar a la llamada Europa de la Restauración, período que dio lugar a una lucha ideológica que dividía a Europa, a favor o en contra de la Revolución, y en el que se produjo la ruptura de aquella ambigüedad que hasta entonces había existido respecto a la Constitución de 1812. La Constitución gaditana empieza a jugar un nuevo papel paradigmático y aparece sin equívoco como una línea divisoria que oponía claramente sus principios a los de la legitimidad y absolutismo de la Europa de la Santa Alianza.

Desde 1814, el pensamiento reaccionario, por su parte, va a desarrollar un ataque sistemático a la misma, dedicándose a poner de manifiesto las contradicciones existentes entre nuestra Constitución y los principios absolutistas, poniendo, por ejemplo, de relieve la antítesis entre soberanía nacional y soberanía real, centrando en el jacobinismo el origen de la Constitución española, destructora como tal del orden social reinante, para terminar dirigiendo a todos los soberanos un encendido llamamiento de lucha contra el jacobinismo y su hija la Constitución (5).

(5) C. L. DE HALLER, "Sulla Constituzione spagnola", Venecia, 1822, citado por J. FERRANDO BADÍA, "La Constitución española de 1812 y el congreso de Verona", Gades, 1812-1987, n. ${ }^{\circ} 16$, Cádiz, 1987, pp. 66-67 y nota 26. 
$\mathrm{Y}$ sin embargo, como es bien sabido, nada hay de jacobinismo (6) en la constitución gaditana ni en todo el proceso de la revolución liberal española. La Constitución de 1812 era, eso sí, una constitución autóctona, no importada, como lo fue en otras partes, por los ejércitos franceses, elaborada para instaurar un orden nuevo y consolidar la revolución liberal, e impuesta al Rey: Esto último le confiere un neto radicalismo, que aparece en el análisis de sus características formales: existencia de una sola Asamblea legislativa que privaba al estamento aristocrático del reducto de la Cámara alta; sufragio universal indirecto en tres grados (parroquia, partido y provincia) que concedía un sistema representativo casi democrático, y que sería durante muchos años el sufragio más amplio de la época; la institución de la Diputación permanente de Cortes para velar por las garantías constitucionales; su concepción de la soberanía nacional, etc. (7). No es cierta, en cambio, la idea de que la Constitución consagraba unas Cortes omnipotentes frente a un rey impotente, puesto que los poderes del rey eran muy amplios. No se olvide que fue una Constitución hecha sin la Monarquía, pero no en contra de la Monarquía, lo que en términos de la época significaba ser una Monarquía Constitucional.

Toda esta serie de características hicieron de ella un cúmulo de singularidades: a) convertirse en modelo de lucha contra los privilegios del Antiguo Régimen en este primer período radical del liberalismo decimonónico; b) ser el único texto semiconstitucional existente en esta primera fase de la Europa de la Restauración, ya que la Carta otorgada francesa de 1814 estaba basada en el principio de legitimidad monárquica y marginaba del poder a las élites burguesas en favor de la aristocracia; y c) convertirse de hecho en el único vehículo legal a través del cual los principios de la revolución francesa siguieron presentes en Europa. El joven liberalismo europeo no buscó ya su programa en los textos franceses, sino que hizo de la Constitución española su inmediata referencia, por lo que se puede decir con toda propiedad que el constitucionalismo liberal del siglo XIX comienza en Cádiz (8).

(6) Me refiero al jacobinismo en el sentido político del término y a su contenido económico-social, tal como lo entendía Gramsci, que define este movimiento radical de la Revolución francesa como la alianza revolucionaria de burguesía y masas campesinas. (7) Para el análisis de la Constitución de 1812 y, más concretamente, de su concepción de la soberanía nacional, véase MARTÍNEZ SOSPEDRA, M., La Constitución de 1812 y el primer liberalismo español, Cátedra Fadrique Furio Cerol, Valencia, 1978, y VARELA SUANZES-CARPEGNA, La teoria del Estado en los orígenes del constitucionalismo hispánico. (Las Cortes de Cádiz), Centro de Estudios Constitucionales, Madrid, 1983. (8) B. MIRKINE-GUETZEVITCH, «La Constitution espagnole de 1812 et les debuts du liberalisme europeen" (Esquisse d' histoire constitutionnelle comparée), Introduction 


\section{1814-1820: LA CONSTITUCIÓN DE 1812: EJE DE LA ES- TRATEGIA REVOLUCIONARIA DEL LIBERALISMO EU- ROPEO}

Toda la resonancia alcanzada por la Constitución de Cádiz que vamos a analizar, tiene su arranque en el hecho de que España, desde 1808, se convierte en escenario ejemplar y privilegiado de la lucha contra el Antiguo Régimen, y en laboratorio de fórmulas tanto teóricas (la Constitución de 1812) como prácticas (ejércitos de guerrillas, pronunciamiento), que han resultado modélicas y se han convertido en verdaderos arquetipos.

Y ello por dos razones: en primer lugar, porque las circunstancias históricas hicieron que España fuera un ejemplo de resistencia nacional contra: Napoleón, resistencia hecha no sólo en nombre de la tradición conservadora, sino también en nombre de la Libertad y la Independencia Nacional.

La segunda razón, es que, por los mismos motivos, España fue matriz del movimiento liberal de la época al elaborar una estrategia de recuperación del poder arrebatado por los absolutistas, consistente en que, a partir del pronunciamiento como dispositivo, se ponía en marcha un proceso insurreccional destinado a reinstalar la Constitución de 1812. Esto fue el pronunciamiento de Riego y su triunfo sobre Fernando.VII en 1820.

De este modo, el tipo de revolución liberal que permaneció dominante en Europa hasta 1830 estuvo basado, en lo político, en la Constitución como objetivo, y en lo organizativo, en la conspiración dentro de las sociedades secretas de corte carbonario, por un lado, y en el pronunciamiento insurreccional basado en el ejército, por otro. Estos fueron los componentes básicos del arquetipo revolucionario que triunfó en España, se extendió a Europa con los movimientos liberales de 1820 y perduró en lo fundamental hasta las revoluciones de 1830.

Este arquetipo que se forjó en España, respondía a una serie de factores comunes que, por encima de la heterogeneidad de las diversas formaciones sociales, actuaban como estímulos revolucionarios en la Europa de la primera etapa de la Restauración, entre 1815 y 1820. Las potencias de la Santa Alianza habían reaccionado a una época sometida a rápidas transformaciones económicas y sociales, tras el doble impacto de la revolución industrial y la revolución francesa, con unos regímenes caducos e inadecuados queriendo así frenar un proceso que era ya irreversible, y que tendía a establecer unas relaciones sociales acordes con el desarrollo del capitalismo. Como respuesta, proliferaron en toda Europa centros y núcleos de oposición dirigida por quienes habían recha- 
zado el régimen napoleónico en nombre de los ideales de libertad, y así, en Alemania, España, Francia, Bélgica, Polonia, Suiza e Italia, la oposición nacional, liberal, democrática y socialista, se unió y se confundió en una lucha más o menos clandestina contra los gobiernos restaurados. Había dos niveles de oposición: una más ideológica, que trataba de desarrollarse dentro de los límites de la escasa libertad de imprenta, y en la que hay que situar la atención dedicada al estudio y conocimiento de la Constitución de 1812, de la que hubo varias traducciones en estos años (9). Al mismo tiempo se vehiculó la acción política a través de las sociedades secretas, agrupaciones clandestinas que desarrollaron un pensamiento político y cuyos objetivos eran cambiar por la fuerza insurreccional el estado de cosas e implantar la constitución. Se enfrentaban al estado político y militarista levantado por las potencias legitimistas, pues excepto en Francia, donde existía un régimen semiconstitucional, no había, claro está, un marco parlamentario de lucha.

La mayoría de estas sociedades tenían su origen en la época napoleónica y todas ellas derivaban del tronco común masónico, aprovechando el ritual y modelo organizativo que había proporcionado la masonería desde la segunda mitad del siglo XVIII. Pero como la más importante de todas ellas fue la Carbonería del sur de Italia, que marcó con su estilo la revolución romántica, se habla genéricamente de sociedades secretas de tipo carbonario, aunque, como es sabido, por ejemplo, en España y Portugal, hubo sólo masonería hasta 1820, y fue después de las revoluciones de 1820 cuando se extendió la Carbonería.

Si entre 1815-1820 convergieron en el seno de estas sociedades secretas todas las corrientes político-ideológicas surgidas con la revolución francesa, todas aceptaban también la común dirección de la élite liberal, élite compuesta por un sector de la nobleza y por la burguesía, puesto que eran las élites burguesas las verdaderas nuevas protagonistas y beneficiarias del proceso de transformaciones socioeconómicas del período 1789-1814, tratando desde entonces de adecuar el reciente poderío económico adquirido al correspondiente poder político.

Este marcó sus objetivos posibilistas y su común estrategia en torno a la Constitución. Es decir, la Constitución representaba asegurar a

á l'étude du Droit composé. Recueil d'articles en honneur d'Edouard Lambert, París, Sirey, 1938, vol. II, pp. 218-219.

(9) J. FERRANDO BADÍA, "Vicisitudes...", pp. 187-188; "La Constitución española...", Gades, pp. 74-75, y M.R. SAURIN DE LA IGLESIA, "Nápoles en el ochocientos: contactos con el constitucionalismo español (1800-1821), Saitabi, XI, Valencia, 1961, pp. 109-110. 
la burguesía el acceso al control del estado y transformar las antiguas monarquías en monarquías constitucionales evitando los radicalismos de la revolución francesa. Y es lo que lograba la Constitución de 1812, colmando las aspiraciones de la burguesía europea y permitiendo además, a través de un sufragio que integraba a la mayoría de la población urbana, dar cabida en ella aspiraciones democráticas más amplias. Gramsci, siguiendo a Marx, profundizaba más en esta reflexión al afirmar que la Constitución gaditana era expresión exacta de la necesidad histórica de la sociedad española y no una aplicación mecánica de los principios de la revolución francesa, subrayando, además, su carácter ejemplar para la Europa ochocentista, porque en ella se dio con la solución jurídico-constitucional más apropiada y más. generalizada de una serie de problemas que no eran sólo españoles, sino comunes a todo el mundo latino (10).

Respecto a estos problemas comunes, hay que tener en cuenta los efectos de la doble revolución en el terreno de la propiedad, en la posesión y en el cultivo de la tierra, que seguía considerándose como principal fuente de riqueza en unas sociedades fundamentalmente agrarias. Las transformaciones revolucionarias que se produjeron en el campo eran a un tiempo condiciones necesarias y consecuencia de la revolución burguesa. El debilitamiento o abolición del feudalismo que se produjo durante el período 1789-1814 supuso, junto al ataque de los bienes comunales de los pueblos y la desamortización de las tierras de la Iglesia un sustancial cambio en el sector agrario, produciéndose una gran transferencia de propiedad en beneficio casi exclusivo de nobles y burgueses. En la mayor parte de la Europa latina, en los Países Bajos, Suiza y Alemania occidental, la abolición del feudalismo fue obra de los ejércitos franceses de ocupación, que aplicaron los principios de la revolución francesa. Pero excepto en aquellas zonas profundamente transformadas por su larga incorporación a Francia, la vuelta de los antiguos regímenes aplazó, por lo general, la puesta en práctica de estos principios abolicionistas, como ocurrió, por ejemplo, en España y Portugal, donde, por lo demás, la restauración de 1814 tuvo menos que restaurar porque había habido menos transformaciones. En Italia, en cambio, aunque las estructuras feudales estaban suprimidas, la burguesía estaba aún lejos del poder político (11).

(10) A. GRAMSCI, Il Risorgimento, Turín, Einaudi, 1949, pp. 131-132.

(11) Sobre las transformaciones económico-sociales que produjo el impacto en Europa de la Revolución y el Imperio, véase el coloquio La abolición del feudalismo en el mundo occidental, Madrid, Siglo XXI, 1979, y A. SOBOUL, Problemas campesinos de la revolución, 1789-1848, Madrid, Siglo XXI, pp. 204-267. 
Desde el punto de vista económico, las economías de estos países, después de 1814, se iban a ver aún más trastornadas por la inadaptación de sus estructuras sociales al desarrollo del capitalismo, que tendía cada vez más a romper los marcos nacionales para convertirse en un sistema mundial. Era la propia expansión del capitalismo mundial lo que desgastaba los viejos sistemas en aquellos países en donde sin estas influencias externas sus contradicciones no hubieran sido tan agudas y distorsionantes, ni hubieran llevado a sus respectivos gobiernos a la quiebra financiera. Estas dificultades económicas del absolutismo facilitaron la acción política de la oposición liberal y daban la razón a las aspiraciones burguesas de acceder al control del estado para imponer una nueva organización social y política, introducir tarifas aduaneras proteccionistas, buscar recursos para la Hacienda con las desamortizacionẹs, con la reforma fiscal contra el privilegio y abolir las trabas que pesaban sobre la producción nacional, como eran el sistema gremial, los diezmos y los derechos feudales.

En España, un aparato político absolutista debilitado por la crisis de 1808-1814 tuvo que enfrentarse, además, a la pérdida de los mercados coloniales, lo que agudizó aún más las dificultades económicas de la posguerra haciendo inviable el retorno a la situación anterior a 1808 (12). Se consolidaron así las propuestas liberales y el prestigio de la Constitución. La serie de pronunciamientos liberales que se sucedieron en España, casi cada año, entre 1814 y 1820 , lograron, en el terreno de la lucha, acuñar la fórmula subversiva que el liberalismo de la época utilizó para imponer a los soberanos de la Europa restaurada el sistema constitucional. No en vano las palabras "liberal" y "pronunciamiento» son de origen español (13).

Estos pronunciamientos de la época, no eran por tanto fenómenos exclusivamente militares, ni siquiera una mera técnica militar, sino pieza básica de una estrategia política al servicio del derrocamiento del absolutismo, donde el elemento militar no sería sino el más adecuado instrumento de materialización del proyecto insurreccional liberal, vértice a la vez de una conspiración de militares y civiles y destinada a la toma

(12) Véase al respecto, J. FONTANA, La quiebra de la Monarquía Absoluta, 1814-1820, Ariel, Barcelona, 1971.

(13) Sobre el término liberal, véase V. LLORENS, "Sobre la aparición de liberal", Nueva Revista de Filología Hispánica, vol. XIII, n. 1 1, 1958, pp. 53-58, y R. LAPESA, "Ideas y palabras: del vocabulario de la Ilustración al de los primeros liberales", Asclepio, 1966, pp. 189-218. Sobre la terminología de "pronunciamiento", C. SECO SERRANO, Militarismo y civilismo en la España Contemporánea, Instituto de Estudios Económicos, Madrid, 1984, p. 45 , nota 48. 
del poder. El jefe militar que se pronunciaba producía el "gesto", daba la señal a toda la Nación mediante un mensaje y una referencia a la Constitución, y desencadenaba así el proceso insurreccional.

Cómo este modelo específico que representa el pronunciamiento español pudo convertirse en estrategia dominante en la lucha liberal de la época, se entiende por las decisivas transformaciones sociales e ideológicas que sufrió el ejército español y en general todos los ejércitos europeos tras las guerras de la Revolución y del Imperio; pasando de ser instrumentos pasivos al servicio de la monarquía absoluta y coto de los privilegiados, a ser un ejército ideológico, identificado con la clase ascendente que hizo la Revolución, expresión. por tanto del espíritu patriótico y nacional, y vehículo, finalmente, de promoción social, como ejemplifica la propia figura de Napoleón, paradigma de la nueva clase burguesa.

En España, la doble experiencia de guerra regular y guerrillas ocurrida entre 1808-1814 produjo un ejército de características propias y populares. La novedad estuvo en que el ejército español se adueñó de este doble legado. Frente al peligro que la guerra de guerrillas representaba, por la movilización del campesinado, el ejército asumió una estrategia insurreccional destinada a controlar al movimiento popular, pero asumía al mismo tiempo, a través del pronunciamiento a favor de la Constitución de 1812, el papel de depositario de la voluntad nacional, de las aspiraciones democráticas y de portavoz de las garantías políticas. De este modo, la Europa de la época de la Restauración vio en el nuevo ejército español el ejemplo de la fundamental transformación operada: al carácter despótico y autoritario del ejército imperial sucedió la experiencia democrática de los pronunciamientos que tuvieron lugar en España después de 1814 en defensa de la Constitución, totalmente distintos al golpe de estado de Napoleón en 1799 (14). La lucha unitaria antiabsolutista que llevaron a cabo, conjuntamente, militares y civiles, hizo posible que ambos hablasen en lenguaje civil, lo que no era difícil, ya que los militares se sentían partícipes de la comunidad civil con la que tenían intereses comunes, entre ellos el de proteger la libertad y la propiedad.

El pronunciamiento se adaptaba por tanto perfectamente a la estrategia constitucionalista de las élites liberales. Élites, porque las masas, ni formaban parte de las conspiraciones ni se quería su participación, sino sólo su apoyo. Este modelo culminó con el éxito del de Riego en la provincia de Cádiz, en Cabezas de San Juan. Su caldo de cultivo inmediato

(14) S. MASTELLONE, Storia ideologica d' Europa. De Sieyès a Marx, Sansoni, Florencia, 1974, pp. 177-187. 
había sido el alto grado de descontento de las tropas que aguardaban en Cádiz el embarque para América. En la conspiración figuraban entre los principales organizadores del movimiento la burguesía mercantil gaditana y los fabricantes de Barcelona, y si el pronunciamiento como tal fracasó al principio, produjo sin embargo el efecto esperado: la insurrección de los principales núcleos urbanos de la geografía española, que extendiéndose como un reguero de pólvora obligaron en marzo de 1820 a Fernando VII a jurar la Constitución gaditana. Constitución, que si hasta entonces había sido motivo de atención, admiración y simpatía en Europa entera, fue desde entonces bandera, estandarte y objetivo de lucha del liberalismo europeo.

\section{1820-1830: PROYECCIÓN DE LA CONSTITUCIÓN DE 1812 E INFLUENCIA DE LA REVOLUCIÓN ESPAÑOLA DE 1820}

Al extenderse por Europa la noticia de que el pronunciamiento de, Riego en la provincia de Cádiz tenía el carácter de una insurrección política que reclamaba el restablecimiento de la Constitución de 1812, la repercusión revolucionaria fue inmediata y amplia, como lo prueban los siguientes hechos: en febrero del mismo año 1820 se produjo el asesinato del duque de Berry, presunto heredero del trono de Francia, descu- , briéndose poco después en el mismo país un complot carbonario que preveía una insurrección en París y en toda Francia, para el mes de agosto.

En julio de 1820, el triunfo de la insurrección carbonaria de Nola, cerca de Nápoles, dirigida por el militar Guillermo Pepe, obligó a Fernando I, rey de las Dos Sicilias, a jurar la Constitución española de 1812, y en agosto de 1820, un pronunciamiento en Oporto conseguía instaurar en Portugal un régimen liberal que elaboraría en 1822 una constitución según el modelo de la gaditana. En Italia, la insurrección se extendió por toda la Península, consiguiendo el Piamonte, en marzo de 1821, imponer también la Constitución de 1812. Si a ello unimos que en febrero-marzo de 1821 la sublevación de los territorios europeos sometidos a Turquía iniciaba en Grecia el movimiento de independencia nacional y que los acontecimientos de la Península Ibérica favorecieron la emancipación de sus colonias americanas, tenemos un claro panorama del impacto mundial de la revolución española de 1820 . Impacto que aún se prolongaría cuando en diciembre de 1825 , aprovechando los problemas creados por la sucesión del zar Alejandro, el pronunciamiento de un grupo de oficiales, los decembristas, intentó sin éxito imponer en Rusia una constitución inspirada igualmente en el modelo gaditano. 
La Europa de la Santa Alianza se planteó con urgencia el encontrar el modo y los medios de frenar esta oleada revolucionaria, viendo como principal causa y prototipo de la misma a la revolución española, de la cual, decía el canciller austriaco Metternich, que «era peor que la francesa de 1789", puesto que ésta había sido local y la española era "europea" (15). Los gobernantes absolutistas creyeron que se trataba de una conjura mundial debida a una especie de Internacional liberal dirigida por las sociedades secretas, cuando, en realidad, los movimientos revolucionarios de los liberales y demócratas europeos se mostraron incapaces de unificar sus esfuerzos, viéndose obligados los diversos grupos nacionales a actuar como una fuerza independiente en cada país. A pesar de la actividad incansable de sus dirigentes y la voluntad de dar una unidad y coordinación racional a la actividad insurreccional en Europa, no existieron organismos directivos eficientes para hacer estallar insurrecciones en cada parte del mundo, como afirmaba la visión policíaca de la época.

Pero lo que sí era cierto es que, efectivamente, los acontecimientos de 1820 introdujeron una nueva dinámica revolucionaria que con la entrada en juego de los intereses respecto a las colonias americanas se transformó de europea en mundial.

En Grecia, todo un pueblo se alzó contra el opresor, pero al unir su lucha con las ideas nacionalistas de la clase media y de la revolución francesa, lo hizo en una forma que podía identificarse con la causa del liberalismo europeo, cuya ayuda sería considerable para el triunfo de la independencia griega en 1829-1830. Pero este movimiento nacionalista sólo era en parte comparable a los movimientos de élites de occidente (16). En Rusia, los decembristas aplicaron plenamente el arquetipo revolucionario español, siendo los primeros grupos de la historia rusa que planearon con metas políticas precisas la toma del poder político, y el primer movimiento subversivo en nombre de la Constitución, la Ley y la Libertad (17).

Pero fue fundamentalmente en la Europa del Sur, en Italia y Por-

(15) G. DE BERTIER DE SAUVIGNY, Metternich et la France après le Congrès de Vienne, II, París. Hachette-Presses Continentales, 1968-1971., p. 600.

(16) .E. J. Hobsbawm, Las revoluciones burguesas; I, Guadarrama, Barcelona, 1980, pp. 253-256.

(17) Sobre los decembristas, MAZOUR, The first Russian Revolution 1825, Berkeley, 1933; I. GREY, "The Decembrist: Russia's first revolutionaries, 1825", History Today, septiembre 1973; Madariaga, I. DE, "Spain and the Decembrists", European Studies Review, vol. 3, n. ${ }^{\circ}$, abril 1973; ORLOV, "El pronunciamiento de los decembristas", Revista militar soviética, n. ${ }^{\circ} 12,1975$, y R. GIRAULT, "La Russie aux XIX et XX siècles», Revue Historique, julio-septiembre 1980. 
tugal, donde triunfó plenamente en 1820 el arquetipo revolucionario español (18).

La localización geográfica de estos movimientos y del impacto de la Constitución de Cádiz se explica precisamente, por un contexto europeo en que los problemas políticos planteados estaban subordinados, en definitiva, a las exigencias de las grandes transformaciones operadas desde el siglo XVIII a raíz de la revolución industrial que se extendía desde Inglaterra al continente. Por ello, tanto las potencias legitimistas de Austria y Rusia como las monarquías constitucionales de Francia e Inglaterra, utilizaban estos pequeños países como mercado de sus productos industriales o como fuentes de materias primas.

Austria tenía un predominio absoluto en la península italiana, dividida en 8 estados por el Congreso de Viena, mientras que en la Península Ibérica, el reparto de influencias respecto al movimiento de emancipación colonial americana que se consumaría en estós años, dejaba a España bajo la tutela de Francia, y a Portugal, sometido a los intereses de su aliada, la corona británica.

Es importante señalar que, a nivel coyuntural, las revoluciones de 1820 siguieron a la crisis agraria que desde 1817 afectó negativamente a todos los sectores sociales, de estas sociedades, y por supuesto, a la clase de mayor peso, la burguesía agraria (19).

Así, los factores que explican la adopción de la Constitución de 1812 en la Italia meridional, es decir, en el Reino de las Dos Sicilias, son, por un lado, como subrayó Gramsci, la similitud de ambas formaciones sociales - es decir, propiedad de la tierra semifeudal, ausencia de transformaciones capitalistas en la agricultura, etc.-, y por otro, la sugestión ejercida por el mito español, sellada con la participación de varios militares napolitanos en nuestra guerra de independencia; un gran entusiasmo españolista que adoptó el bajo pueblo hacia una constitución que, aun sin apenas conocerla, era considerada como la portadora de las ideas más democráticas de Europa. Por último, razones de oportunidad, ya que convenía aprovechar la claudicación regia y cubrir la urgencia del

(18) Sobre las revoluciones de 1820 en Italia, véase, entre otras obras, las de A. LEPRE, La rivoluzione napoletana del 1820-21, Editori Riuniti, Roma, 1967, y G. CANDELORO, "L' ondata rivoluzionaria del 1820-21", cap. $2{ }^{\circ}$ del vol. II (1815-1846) de su Storia dell' Italia Moderna, Feltrinelli, Milán, '1978. Sobre Portugal, M. FERNÁNDEZ TOMÁS, A revoluçâo de 1820, ed. de José Tengarrinha, Seara Nova, Lisboa, 1974; F. PITEIRA SANTOS, Geografia e Economia de Revoluçâo de 1820, Europa-América, y V. DE SA, A crise do Liberalismo (1820-1852), Horizonte, Lisboa, 1978, pp. 27-88. (19) J. FONTANA, «La crisis agraria de comienzos del siglo XIX y sus repercusiones en España", Hacienda Pública Española, n. ${ }^{\circ}$ 55, 1978. 
momento acudiendo a un código ya existente, sobre cuyo modelo se promulgó en 1821 la Constitución de las Dos Sicilias y se desarrolló una intensa actividad legislativa que duró lo que el régimen constitucional, esto es, : cerca de un año (20). En el resto de Italia, concretamente en el Piamonte, se adoptó la constitución española, fundamentalmente, porque ya se había hecho en el Sur, en un intento unificador de objetivos. Y si en el Piamonte ni la revolución de 1821 ni la adopción del estatuto gaditano tuvieron los caracteres de un acontecimiento de masas, como sucedió en Nápoles, y fue muy pronto criticada por dirigentes liberales moderados de la revolución piamontesa, testimonios de la época nos explican la inmensa audiencia de la constitución gaditana después de la revolución, y cómo las librerías no podían satisfacer las demandas que de ella se hacían. Hasta tal punto la revolución de 1820 puso de moda en Europa la constitución gaditana (21).

Sin entrar en el detalle de estos regímenes liberales, sí conviene aludir, por lo que incide en la trayectoria posterior de la Constitución de 1812 , a las causas del fracaso generalizado de estas experiencias. Hay que mencionar, en primer lugar, la inmadurez de las clases revolucionarias, debido a la debilidad e incluso ausencia de burguesía industrial y consiguiente peso excesivo de la burguesía agraria, cuyos intereses predominaron en los respectivos parlamentos en detrimento de otras fracciones burguesas. Eso, en el caso italiano, impidió que se abordaran con' seriedad los problemas desde una perspectiva italiana, y no local, de lucha; mientras que, en el caso portugués, propició que un gran sector liberal acabase colaborando con las fuerzas del Antiguo Régimen en el golpe de estado de la Vilafrancada, en mayo de 1823 , contra el radicalismo de la Constitución de 1822 y a favor de un sistema de carta otorgada, con el apoyo y beneplácito de Inglaterra. Pero la radicalización de las fuerzas absolutistas, ante la ausencia de transformaciones revolucionarias, restauró de nuevo el absolutismo. La derecha liberal portuguesa se equivocó, y pagó su error sufriendo desde 1823 un período de represión y exilio.

En comparación con la portuguesa, la burguesía española era más radical; obligada como estaba a hacer frente con urgencia, tras la pérdida de las colonias americanas, a los problemas derivados de una necesaria industrialización. En 1820 el liberalismo reflejaba más que en 1812

(20) M.R. SAURIN DE LA IGLESIA, op. cit., pp. 110-111.

(21) J. FERRANDO BADÍA, "Vicisitudes...», y «La Constitución española de 1812 en los comienzos del Risorgimento", en Cuadernos del Instituto Jurídico Español, n. "10, 1959, pp. 1-142. 
las distintas fracciones de clase de quienes lo sustentaban, y el hecho de que por primera vez se veían en el trance de aplicar la obra legislativa de las Cortes de Cádiz. Todo ello acabaría por afectar a la teoría constitucional de Cádiz. Sin embargo, el peso de la burguesía agraria seguía siendo también decisivo, mostrando, como en Italia y Portugal, la debilidad reformista de unos regímenes que ignoraron la dimensión social del problema agrario. Decepcionaron así a un campesinado poco familiarizado con los principios constitucionales, y que sólo hubiera entendido un cambio político que les hubiera supuesto la baja de las contribuciones y el acceso a la tierra. De la ignorancia que éstos tenían de lo que significaba la palabra misma constitución, habla la conocida anécdota de la época, común a los soldados rusos de San Petersburgo y a los campesinos catalanes, según la cual, al oírse el grito de Viva la Constitución, creyeron unos que se trataba de la mujer del duque Constantino, y los otros, del nombre de la nueva esposa de Fernando VII. De esta limitación social y reformista se resintieron estos regímenes liberales, que no pudieron movilizar a un campesinado contra la nueva ocupación extranjera, como había sucedido en España en 1808.

Un segundo elemento que explica el fracaso de estos regímenes es el de la división entre moderados y radicales en el propio seno de la familia liberal. En el caso español, la Constitución de Cádiz había sido, entre 1814-1820, un programa de entendimiento, entre los liberales sublevados en 1820 , pero entre 1820-1823, una vez en el poder, surgieron ideas de reforma a la derecha y a la izquierda, sin contar con que el comportamiento de Fernando VII, apoyado con frecuencia por la propia derecha liberal, planteó constantes conflictos entre la Corona y las Cortes, entre el ejecutivo y el legislativo.

Por último, el intervencionismo militar de la Santa Alianza contra los regímenes liberales fue el tercer factor que decidió la derrota de éstos. Intervencionismo que era lógico, puesto que desde el primer momento todas las grandes potencias habían considerado que la adopción del modelo de la Constitución gaditana por parte de las revoluciones triunfantes, era un peligro para la estabilidad europea y para la seguridad de los tronos, por sus aspectos radicales que llevaban inexorablemente "a la libertad completa, o provocaba, como reacción, el absolutismo puro" (22), en expresión de un libeial moderado de la época.

El hecho es que, la vida política europea entre 1820-1823, estuviera en gran medida condicionada por la Constitución de Cádiz (23). Los ga-

(22) M.R. SAURIN DE LA IGLESIA, op. cit., pp. 109-110.

(23) J. FERRANDO BADÍA, "La constitución española de 1812 y el Congreso de Verona", pág. 77. 
binetes de Francia, Austria, Prusia y Rusia presionaron con mayor fuerza sobre los liberales españoles para que la reformaran, sobre todo después que la intervención austriaca había acabado violentamente con los gobiernos liberales de Nápoles y el Piamonte en la primavera de 1821. Pero los liberales españoles rechazaron la intromisión de los gobiernos extranjeros en sus asuntos internos, negándose a la reforma de la Constitución. Sabían que esta actitud conduciría a la intervención extranjera contra el régimen constitucional español, desgracia que se produjo a cargo de los ejércitos franceses; que mandados por el duque de Angulema penetraron en España en abril de 1823, obligando a las Cortes a retirarse a Sevilla primero y después a Cádiz, hasta que la célebre batalla de Trocadero, el 31 de agosto de 1823, obligó al gobierno constitucional a capitular.

En todo este proceso muchos militares y políticos constitucionales, los más propicios a pactar con la aristocracia terrateniente y con las fuerzas del Antiguo Régimen, claudicaron convencidos de que los franceses impondrían un régimen moderado como existía en la Francia de la Restauración, pidiendo al propio Fernando VII que interviniera como mediador ante las tropas francesas. Pero el monarca español, una vez liberado de la tutela del gobierno constitucional, anuló nuevamente el 1 de octubre de 1823 la Constitución española y restableció el gobierno absoluto. Ello mostraba el fracaso de la estrategia constitucionalista, que se basaba en el intento de conciliar lealtad dinástica y revolución liberal, mediante algún tipo de monarquía constitucional. Intento inviable sin la colaboración del rey.

Tanto en España como en Italia o Portugal, los monarcas no habían dejado de conspirar con las fuerzas absolutistas europeas desde 1820 , a la sombra de la Santa Alianza. Sobre la actitud intransigente de Fernando VII existe otra anécdota relevante: cuando el moderado Martínez de la Rosa le presentó un proyecto de constitución que contemplaba desde el punto de vista de la moderación una Constitución de dos Cámaras, el rey exclamó: “¿Cómo? ¿Dos Cámaras? ¿Dos Cámaras, cuando no podemos con una? ¿Jamás! No acepto tu Constitución» (24).

España fue el último régimen liberal en caer, y una vez más ejercició el papel de modelo, acogiendo esta vez a los prófugos italianos después de 1821, los cuales, con otros liberales europeos, defendieron hasta el final la Constitución de Cádiz contra los ejércitos franceses.

Las distintas posiciones ante la Constitución de 1812 por parte de los liberales, se mantuvieron en el exilio después de 1823. Por razones

(24) F. FERNÁNDEZ DE CÓRDOVA, Mis memorias íntimas, I, Madrid, 1886, p. 51. 
prácticas, y en atención a quienes podían sentirse atemorizados por los aspectos radicales de la Constitución gaditana, ésta dejó de reivindicarse, viéndose sustituida por un genérico régimen constitucional, aplazándose para después de la toma del poder la formulación de su contenido. Esto no impidió que la Constitución gaditana siguiera conservando su poder de movilización. Y así, en las tentativas insurreccionales de los liberales españoles de la década de los 20 , volvió a imponerse el grito de ¡Viva la Constitución de 1812!

Por lo demás, el intervencionismo militar de la Santa Alianza, que había expulsado violentamente del poder a los liberales, hizo que se continuase actuando en el exilio europeo en términos de 1820, a pesar de que los cambios experimentados en la sociedad europea de estos años requerían otro tipo de estrategia revolucionaria. La fuerza simbólica de la Constitución gaditana siguió alimentando el radicalismo político de los liberales, abocados a una lucha violenta contra el absolutismo.

Sólo a partir del triunfo definitivo del liberalismo moderado de las revoluciones de 1830, que asestaron un golpe definitivo a la Europa de la Santa Alianza, la Constitución de 1812 cedió en influencia a la de otros textos constitucionales posteriores, tales como la Constitución francesa de 1830, que democratizaba la Carta de 1814, y la Constitución belga de 1831, también bicameral, que desde entonces se convirtieron en el nuevo modelo de los liberales europeos (25).

En España, siguió reivindicándose todavía la Constitución de Cádiz, coincidiendo con los momentos más radicales de la revolución liberal. Fue impuesta a la regente María Cristina en agosto de 1836 hasta que la nueva Constitución, mucho más moderada, de 1837 consagró en nuestro país, de modo irreversible, el sistema constitucional.

La Constitución gaditana, sin embargo, no perderá nunca su fuerza mítica y su contenido revolucionario. No en vano fue el texto de educación cívica de los españoles, un texto por el que se luchó y se murió, un texto que había enseñado a los liberales de la Europa entera, que lo primero, es ser libres.

(25) B. MIRKINE-GUETZEVITCH, op. cit., p. 219. 